\title{
SISTEM INFORMASI PENGAGENDAAN SURAT BERBASIS WEB PADA PENGADILAN TINGGI MEDAN
}

\author{
Hengki Tamando Sitohang \\ Teknik Informatika \\ STMIK Pelita Nusantara, Jl. Iskandar Muda No.1 Medan, Sumatera Utara, Indonesia 20154
}

hengki_tamando@yahoo.com

\begin{abstract}
Abstrak
Banyak jumlah surat yang diterima dan yang dikirim oleh pengadilan tinggi medan bagian umum dan informasi, sehingga saat ini diperlukan suatu sistem yang dapat membantu kinerja yang berkaitan dengan suratmenyurat, maka penulis tertarik merancang sistem informasi pengagendaan surat. Pengagendaan surat adalah catatan surat masuk dan surat keluar yang diterima maupun yang dikirim dalam dua buku maupun satu buku. Pengagendaan surat biasanya termasuk pekerjaan dari bagian umum, pegawai, sekretaris. Surat adalah sarana komunikasi untuk menyampaikan informasi dari satu kepada pihak yang lainnya. Pembuatan Sistem Informasi Pengagendaan Surat berdasarkan perancangan sistem yang telah disusun yaitu use case diagram, activity dan class diagram. Bahasa yang digunakan adalah bahasa PHP, database MySQL, tempat menjalankan PHP menggunakan Dreamweaver dan menjalankan program menggunakan Xampp Control. Pengadilan Tinggi Medan masih menggunakan sistem yang konvesional. Sehingga sangat diharapkan agar sistem ini dapat berjalan dengan baik serta dapat membantu kinerja pada pengadilan tinggi medan mengenai surat menyurat.
\end{abstract}

Kata kunci : Sistem Informasi, Surat, PHP, MySQL, Xampp

\section{Abstract}

Many letters received and sent by pengadilan tinggi medan the general and information, so now requared a system that cal help performance related to the correspondence, the authors are interested to desaign information systems agenda a letter. Agenda letters is the records incoming mail and outgoing mail received and sent in two books and a book. Agenda letter usually including job than the a general,employees and secretaries. Letters are the means of communication to convey information by the parties to the other. Making of information system agenda letter based design system has composed ie use case diagram, activity and class diagram. The language used is language PHP, database MySQL, place run PHP using dreamweaver and run the program using xampp control. Pengadilan Tinggi Medan still using system convesional. The very expented that the system can run well as well as can help the performance of the pengadilan tinggi medan about the correspondence.

Keyword : Information system, Letter, PHP, MySQL, Xampp

\section{PENDAhuluan}

Perkembangan teknologi yang semakin pesat sekarang ini menuntut kita untuk mengikuti arus perkembangan teknologi tersebut, begitu juga bagi instansi akan melakukan modernisasi administrasi, seperti pemanfaatan teknologi komputer salah satunya adalah sistem informasi pengarsipan surat masuk dan surat keluar. Bertujuan agar setiap pekerjaan dapat dilakukan dengan mudah dan cepat dengan hasil yang maksimal dalam hal surat-menyurat di instansi pemerintahan, salah satu yang akan melakukan medernisasi administrasi adalah Pengadilan Tinggi Medan. Pengadilan Tinggi Medan menerima banyak jenis surat yang berbeda lalu menuliskan atau mencatat beberapa bagian dari surat tersebut yaitu: nomor surat, uraian surat, asal surat, tanggal surat masuk,tanggal surat keluar, tanggal agenda, dokumen. Adapun terdapat masalah-masalah pada instansi tersebut seperti pengarsipan yang masih dilakukan dengan cara menuliskan ke buku besar dan masih lambat kemudian didata dengan cara mencatat kedalam buku besar dan perlu mengirimkan balasan yang berbeda pula dengan demikian maka dalam mencari surat tersebut jika sewaktu-waktu dibutuhkan maka itu akan mengurangi keefesienan dalam hal tenaga dan waktu bila dilakukan dengan cara menulis satu persatu ke buku agenda.

Pengagendaan surat masuk dan surat keluar pada kantor Pengadilan Tinggi Medan masih menggunakan sistem pengarsipan yang konvesional. Proses yang dilakukan masih dengan cara memisahkan antara surat masuk dan surat keluar

dikarenakan jumlah data yang sangat banyak jika data tidak dikelola dengan baik, teliti dan teratur, maka akan menimbulkan suatu permasalahan, sehingga diperlukan pembuatan sistem informasi yang mendukung kinerja dari pada Instansi pemerintah yang bersangkutan. 
Berdasarkan latar belakang diatas maka identifikasi masalah dalam penelitian adalah ditemukannya kesulitan dalam hal surat keluar yang akan dikirimkan, karena jenis masalah surat dicatat pada buku agenda yang sama, dokumentasi surat belum optimal sehingga berkas-berkas akan mudah hilang dan rusak. Batasan masalahdari penelitian ini adalah Surat masuk dan surat keluar yang dapat diagendakan menggunakan sistem ini adalah surat yang berasal dari dalam maupun dari luar instansi. Dari masalah yang telah teridentifikasi tersebut dengan demikian penulis membuat rumusan. Bagaimana merancang sistem informasi pengagendaan surat

\section{TEORI}

\section{a. Defenisi Sistem}

Sistem merupakan suatu jaringan kerja dari prosedur-prosedurnya yang saling berhubungan, berkumpul bersama-sama untuk melakukan suatu kegiatan atau untuk menyelesaikan suatu sasaran tertentu.

\section{b. Informasi}

Informasi adalah data yang telah diolah menjadi bentuk yang lebih berguna bagi yang menerima

\section{c. Sistem Informasi}

Sistem Informasi adalah kumpulan elemen yang saling berhubungan satu sama lain yang membentuk satu kesatuan untuk mengintegrasikan data, memproses dan menyimpan serta mendistribusikan informasi.

Menurut (Sapto Aji, Migunani, Fitro Nur Hakim, 2014). Sistem informasi memiliki komponenkomponen yang terdapat didalamnya yaitu terdiri dari blok masukan, blok model, blok keluaran, blok teknologi, blok basis data, blok kendali (Sapto Aji, Migunani, Fitro Nur Hakim, 2014 ).Berikut penjelasnnya berupa gambar:

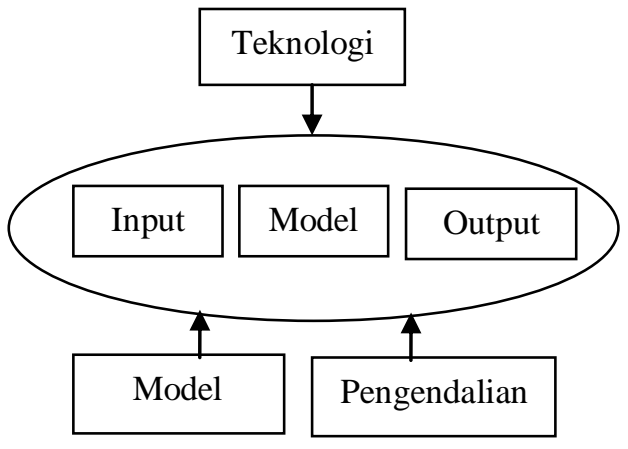

Gambar 1. Komponen Sistem Informasi

\section{d. Surat}

Surat adalah alat komunikasi tertulis yang berasal dari satu pihak dan ditujukan kepada pihak lain untuk menyampaikan warta. Surat bersifat praktis yang artinya dapat menyimpan berbasis web pada Kantor Pengadilan Tinggi Medan?

Tujuan dari penelitian yang dilakukan adalah untuk membuat sistem informasi pengagendaan surat pada Kantor Pengadilan Tinggi Medan. Agar dapat mempermudah para pengelola surat menggunakan sistem informasi yang disesuaikan dengan kebutuhan yang ada serta manfaat dari pembuatan sistem informasi ini adalah dapat menambah pengetahuan dalam pembuatan sistem informasi berbasis web menggunakan PHP dan dalam pengelolahan database menggunakan MySQL.Mempermudah kinerja sehingga dapat memininkan waktu agar efesiensi kerja mengalami peningkatan.

rahasia, efektif artinya sesuai dengan keadaan yang sebenarnya dan ekonomis artinya biaya pembuatan, peralatan dan pengirimannya murah. Fungsi surat adalah Sebagai sarana dalam penyampaian pesan secara tertulis, surat berperan dalam mencapai tujuan suatu instansi atau organisasi dalam menjalin kerjasama antar organisasi/instansi. Sebagai pemberitahuan, sebagai surat perintah, sebagai surat peringatan, Sebagai surat permohonan atau permintaan, sebagai surat pengantar, sebagai surat perjanjian, Sebagai surat laporan, Sebagai surat keputusan, sebagai surat panggilan, sebagai surat susulan.

Surat masuk adalah surat-surat yang diterima oleh suatu organisasi, baik dari organisasi lain atau perseorangan. Berikut proses penanganan surat masuk

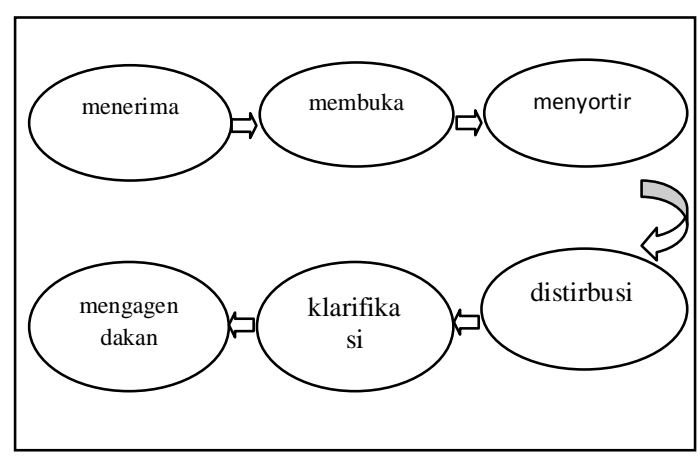

Gambar 2.Proses penanganan surat masuk

Surat keluar adalah surat yang dikirim dari pihak baik instansi, organisasi atau perusahaan yang berisi tentang suatu informasi atau data baik itu perintah, pemberitahuan maupun informasi lainnya.

\section{e. Agenda}

Agenda adalah catatan keluar masuknya surat yang dikirim maupun yang diterima oleh suatu instansi/organisasi.

\section{f. PHP adalah PHP (Hypertext Preprocessor)}


PHP adalah PHP (Hypertext Preprocessor) adalah bahasa pemrograman web berbasis server (server slide) yang mampu memparsing kode PHP dari kode dengan ekstensi PHP sehingga menghasilkan tampilan website yang dinamis disisi client (Edy Winarno, Ali Zaki dan Smitdev Community, 2014)

\section{g. MySQL (My Structure Query Language)}

MySQL (My Structure Query Language) adalah sebuah software database, yang merupakan tipe data relasional yang artinya MySQL penyimpanan datanya dalam bentuk tabel-tabel yang saling berhubungan.

\section{III.HASIL DAN PEMBAHASAN}

a. Implementasi Sistem

Implementasi sistem merupakan tahapan dalam menerapkan sistem yang telah dibangun, dimana nantinya akan diketahui kualitas dari sistem yang dirancang, apakah sudah dapat berjalan dengan baik dan sesuai dengan tujuan yang diharapkan. Berikut adalah tampilan login dari sistem yang telah dirancang:

Halaman Tampil Login

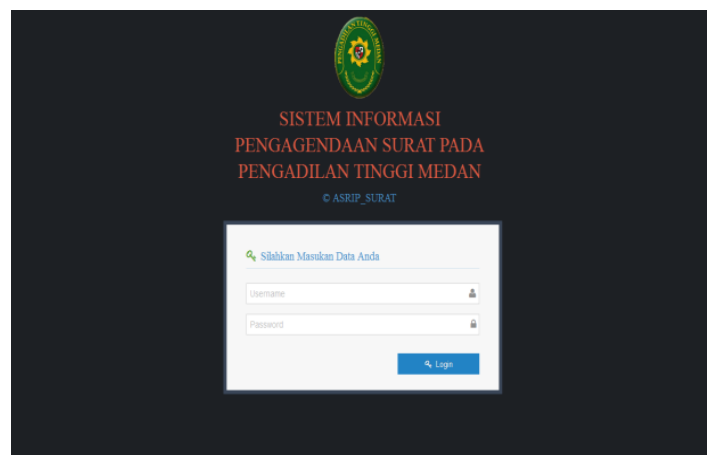

Gambar 3. Tampilan login

Halaman Utama Admin

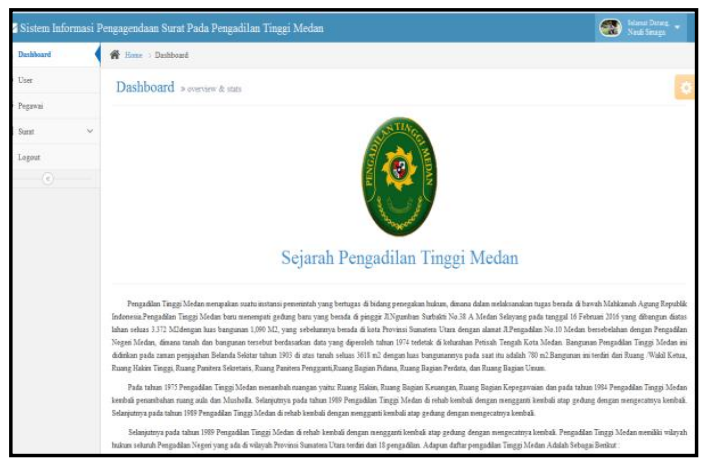

Gambar 4. Halaman Utama Admin

\section{h. XАMPP}

XAMPP adalah salah satu paket instalasi apache, PHP, dan MySQL secara instant yang dapat digunakan untuk membantu proses instalasi ketiga produk tersebut.

\section{i. UML (Unified Modeling Language)}

UML (Unified Modeling Languege) memiliki sintaks dan semantic". Ketika kita membuat model menggunakan konsep UML (Unified Modeling Languege) ada aturan-aturan yang harus diikuti. Bagaimana elemen pada modelmodelyang kita buat berhubungan satu dengan lainnya harus mengikuti standar yang ada.

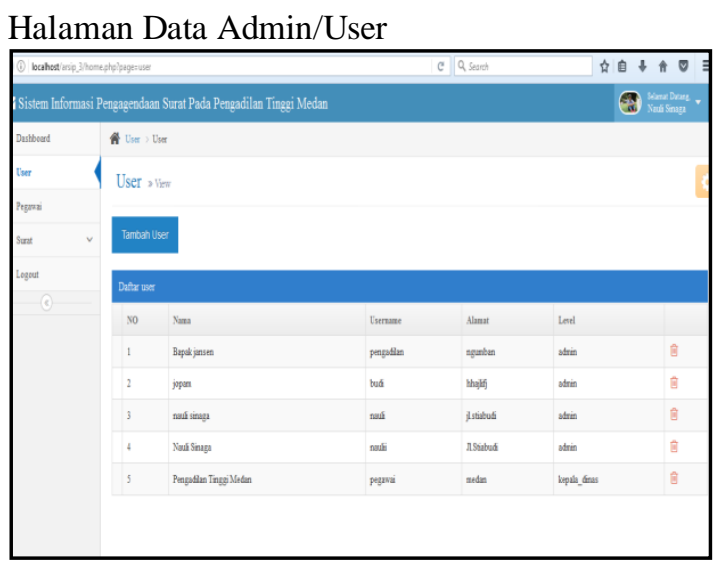

Gambar 5. Halaman Data Admin/user

Halaman Data Pegawai

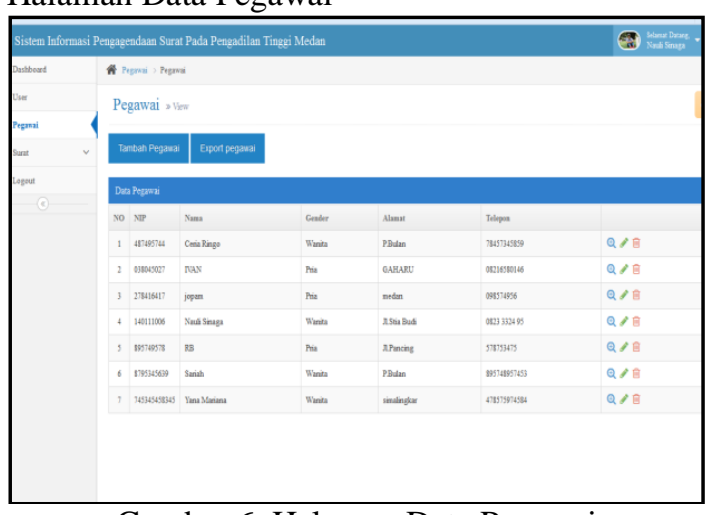

Gambar 6. Halaman Data Pegawai

Halaman Data Surat Masuk

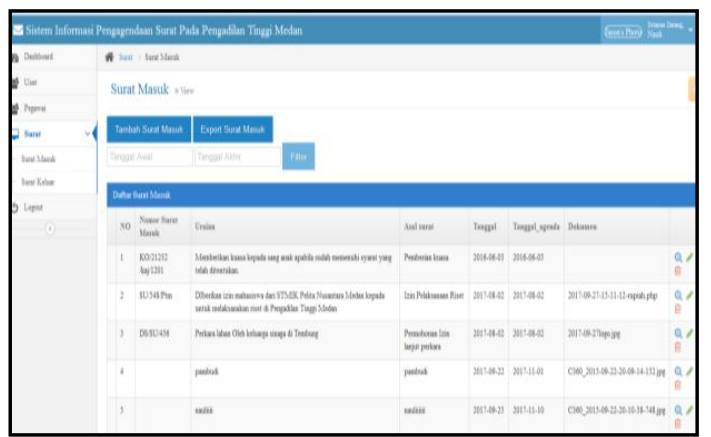

Gambar 7. Halaman Data Surat Masuk 


\section{Halaman Data Surat Keluar}

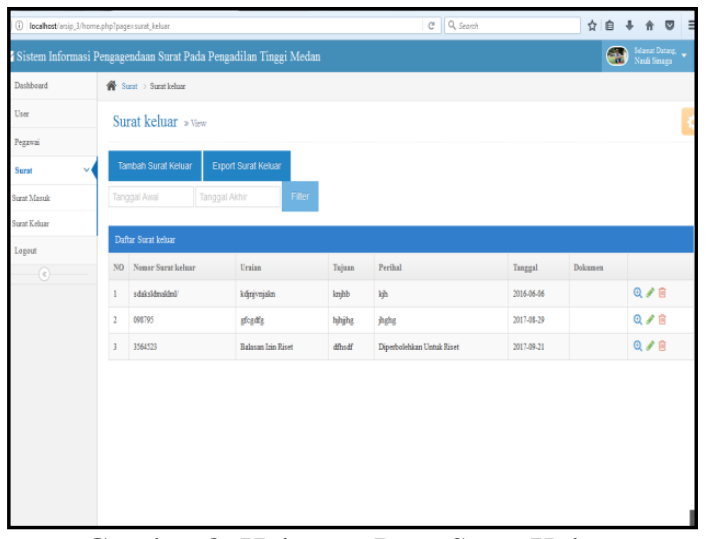

Gambar 8. Halaman Data Surat Keluar

\section{IV.KESIMPULAN}

Berdasarkan hasil penelitian yang telah dilakukan penulis dapat menyimpulkan sebagai berikut:

1. Pengolahan data surat yang belum terkomputerisasi menyebabkan ketidakteraturan pencatatan surat masuk dan keluar yang merupakan salah satu penyebab ketidaklancaran kegiatan proses surat menyurat.

2. Sistem Pengelolaan Surat Masuk dan Surat Keluar Terkomputerisasi adalah sebagai sarana informasi bagi para pegawai bagian persuratan agar dapat mempermudah dalam pengelolaan surat.

\section{REFERENSI}

[1] Agus Prayitno dan Yulia Safitri, Pemanfaatan Sistem Informasi Perpustakaan Digital Berbasis Web untuk Para Penulis, 20151(11), 2-3

[2] Bibit dan sukadi, Sistem Pengolahan Surat Masuk dan Surat Keluar Terkomputerisasi Pada Unit PelaksananTeknik (UTP) Sekolah Menengah Pertama (SMP) Negeri 1 Tegalombo, apmmi, 2015,4(2),1-35

[3] Dewi L., R. Rancangan Aplikasi Sistem Persuratan Berbasis Web pada PT Dwi Pilar Pratama, Perancangan Aplikasi Sistem Persuratan, 2014,7(3),25-27

[4] Edy,W., Ali, Z., Smitdev, C. 2014. Pemrograman Web Berbasis HTML5,PHP \& Javascript. Jakarta: PT Elex Media Komputindo.

[5] Mia Rosmiati, Analisis dan Perancangan Eservice untuk Pelanggan pada Jaya Bersama Konveksi, 2015, 1(1),2-3.

[6] Sapto, A., Migunani., Fitro, N H. Rancangan Bangunan Sistem Informasi Disposisi Surat Berbasis Web (Studi Kasus Kementerian Pekerjaan Umum),Program Studi Teknik Informatika STMIK Provinsi, Semarang, 2014,3(3),25-27 